VISUAL EXPERIMENT

\title{
Mouse model of DNCB-induced atopic dermatitis
}

\author{
Alshammari Fanar Hamad, Jong-Hun Han and Irfan A. Rather \\ Department of Applied Microbiology and Biotechnology, School of Biotechnology, Yeungnam University, \\ Gyeongsan, Gyeongbuk 712-749, Republic of Korea.
}

Correspondence to Irfan A. Rather at rather@ynu.ac.kr; erfaan21@gmail.com

Published: 30 April, 2017

DOI: 10.3329/bjp.v12i2.31950

\section{ABSTRACT}

Atopic dermatitis is a skin disease characterized by allergic skin inflammation, redness and itching. The animal model is necessary to find out new drugs. The DNCB-induced animal model of atopic dermatitis includes the following steps: 1) Selection of animals; 2) Shaving of dorsal skin; 3) Applying DNCB once in 24 hours for three days; 4) Monitoring the development of atopy on day 4 post DNCB application. Further, the efficacy of reference drug can be determined by applying on the atopy skin, depends on the nature and aim of the work.

\section{INTRODUCTION}

Atopic dermatitis is a chronic allergic disease of the skin characterized by inflammation and rashes. It is also known as eczema. There is an abnormality in the immune system. In $>80 \%$ of the cases in children, the serum IgE level is increased which is due to the impaired balance of the CD4-positive T-helper cell populations Th1 and Th2 with a predominance of IL- 4 and IL-13 producing Th2 cells. This disease does not have any permanent or long-term treatment. Therefore, an animal model is necessary to understand the pathogenesis of this disease and also to find out an effective drug.

A large number of new drugs are synthesized but fail to establish in the clinical trials. Most of these failures are due to a variety of reasons, including inadequate efficacy, safety and tolerability. This most probably reflects the predictive quality of the preclinical animal models and the difficulty in translating positive data in animal models to the patient (Nolte et al., 2013).

In the present visual experiment, a mouse model of DNCB-induced atopic dermatitis has been described.

\section{MATERIALS AND EQUIPMENTS}

1. 1-Chloro-2,4-dinitrobenzene (DNCB)

2. Acetone

3. Olive oil

4. Electric shaver

5. Hair removing cream to remove some unwanted hair left

6. Applying brush

7. Weighing balance

8. Pipette and tips

9. Aluminum foil

10. Autoclave

11. Air shower* and UV chamber* (*if working in pathogen free lab).

12. Gloves 

13. Lab coat
14. Aluminum foil
15. $70 \%$ ethanol
16. Vortex

\section{PREPARATION OF REAGENTS}

DNCB (1\% and 2\%): Dissolve $100 \mathrm{mg}$ DNCB powder in $20 \mathrm{~mL}$ of acetone/olive oil (4:1; v/v) solution (2\%). Half dilution makes the solution $1 \%$.

\section{VIDEO CLIP}

DNCB-induced atopic dermatitis: $8 \mathrm{~min}$

\section{PROTOCOL}

1. In order to synchronize the conditions of experimental mice, they were maintained in isolation in pathogen-free conditions for two weeks.

2. Keep two mice per cage in order to avoid fight.

3. For acclimatization, mice were kept at a constant temperature of $23^{\circ} \mathrm{C}$ and humidity (55\%) with a 12 hour light/dark cycle.

4. Mice were fed with basic laboratory diet and water ad libitum.

5. After two weeks of adaptation period, mice were subjected to induction of DNCB-induced atopic dermatitis.

6. The procedure was started by carefully shaving the hair off from the dorsal skin region with a fine electric shaver. Apply hair removing cream if required to remove the rest of the hair.

7. In order to sensitize the skin and for the induction of atopic dermatitis, $100 \mu \mathrm{L}$ of $1 \%$ DNCB in $4: 1$ (v/v) acetone/olive oil solution was topically applied once daily to the exposed skin for two days.

8. Apply $120 \mu \mathrm{L}$ of $2 \% \mathrm{DNCB}$ on day 3 .

9. After the visual confirmation of parameters for skin sensitization, mice were treated with test samples.

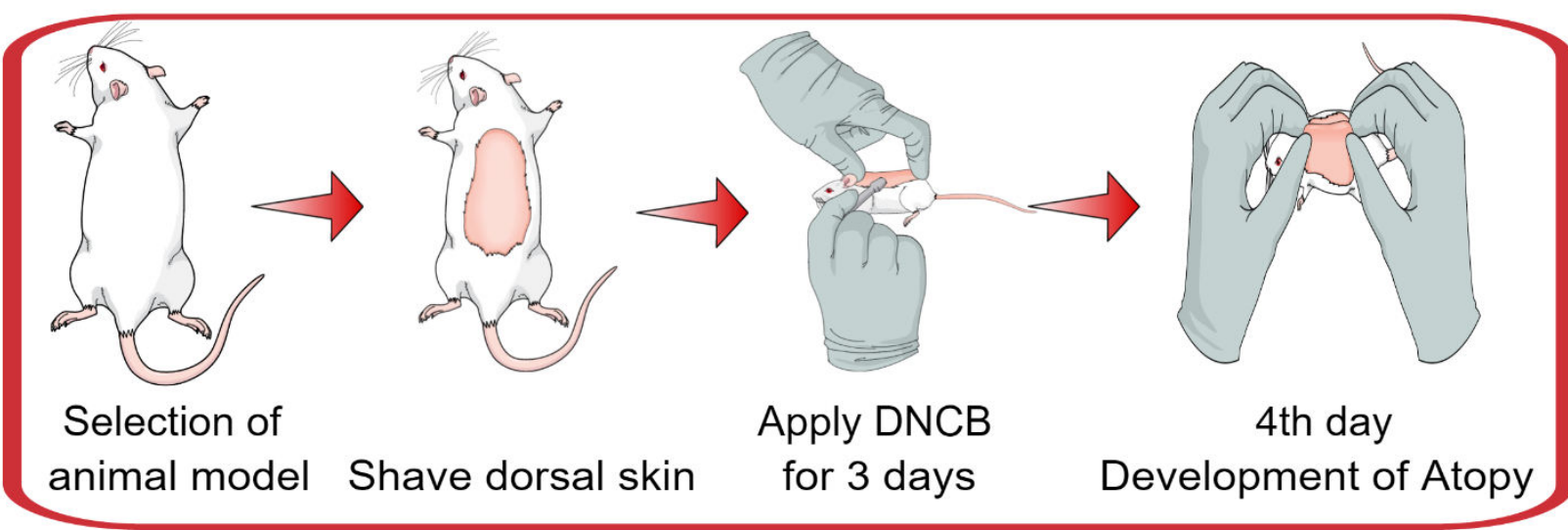

Figure 1: Schematic of DNCB-induced atopic dermatitis in mice model 


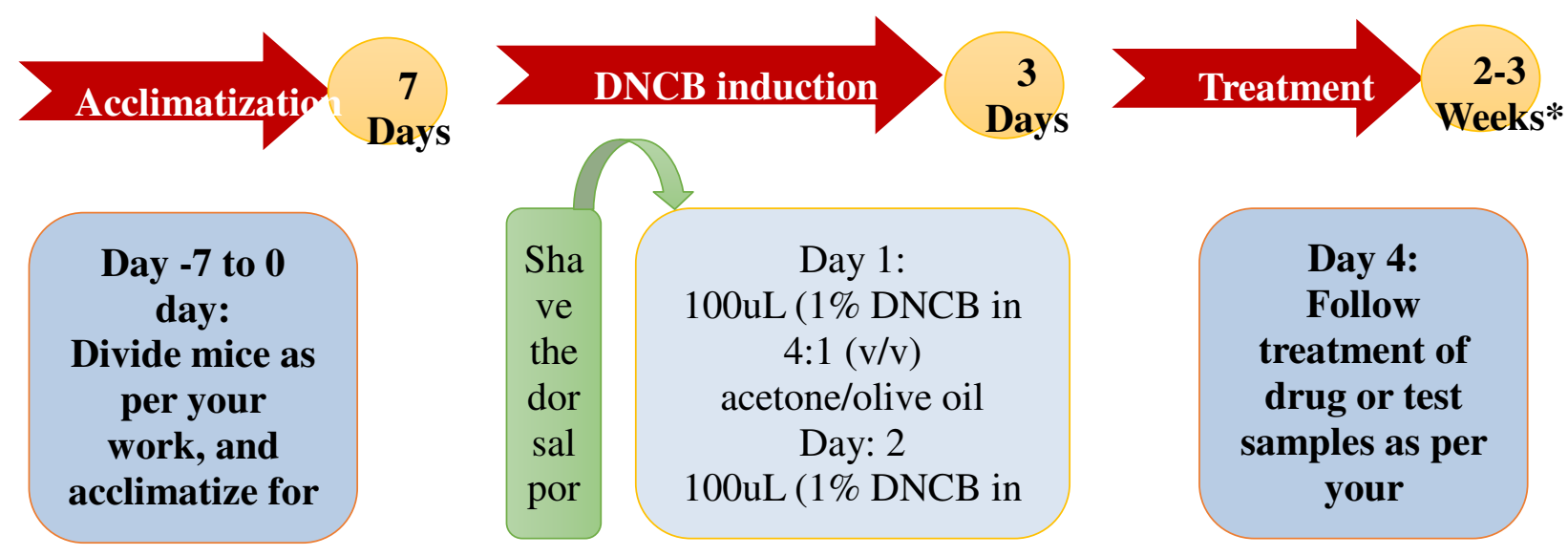

Figure 2: Flowchart of DNCB-induced atopic dermatitis in mice model

\section{DISCUSSION}

In case of developing in vivo animal model of human disease of atopic dermatitis, we must consider the following points like a) Model organism displays the main clinical symptoms of the disease; b) Induction of the disease phenotype is reproducible; c) Possible transfer of data to man (Gutermuth et al., 2004).

Among the animals of atopic dermatitis, the mouse, guinea pig (Fukuda et al., 2003), cat (Schleifer and Willemse, 2003), dog (Mueller et al., 2004) and horse (Lorch et al., 2001) are used. Mouse model of atopic dermatitis gets wider acceptance. The manipulation of the mouse is easier than the cat or dog.

In the case of mouse, there are three options: a) Use of mouse (NC/Nga) that spontaneously develop atopic dermatitis-like skin lesion; b) animal model induced by epicutaneous application of sensitizer and c) transgenic mouse that either overexpress or lack selective molecule (Jin et al., 2009).

Use of spontaneous NC/Nga mouse can produce atopic dermatitis similar to human one. But it is difficult to breed (Tanaka and Matsuda, 2006). Epicutaneous application of sensitizer inducible model is easy to manage but represents only a part of the disease. Similarly, the transgenic mouse also represents only a part of the disease.

The advantages of using mouse model for atopic dermatitis are: a) Small size; b) Relatively low housing cost; c) Short generation time; d) large number of offspring; e) Availability of inbred strains; f) Knowledge about immune system and skin physiology; g) Availability of genetically altered mice to study gene function (transgenic, conditional knock out, knock in, etc.); h) Environmental factors (housing, feeding, day-night rhythm, climate, stress, etc.) (Gutermuth et al., 2004).

The criteria for mouse models of atopic dermatitis include clinical symptoms (dryness, scaling, erythema, erosion and excoriation), pruritus (scratching behavior), elevation of total and specific IgE and increased mast cells in the upper dermis (Matsuoka et al., 2003).

The most convenient, low-cost and reproducible one is the use of epicutaneous sensitizer. Several sensitizers are recommended of which the commonly used are: i) ovalbumin; ii) microbial antigen (mite, Staphylococcus aurius); iii) chemical compounds (picryl chloride, oxazolone, trinitrochlorobenzene, 1chloro-2,4-dinitrobenzene) (Lee et al., 2010). In the present visual experiment, we have shown step by step procedure of DNCB-induced mouse model of atopic dermatitis.

However, no mouse model fully mimics all clinical manifestations of the human allergic skin diseases (Takeda and Gelfand, 2008). The model only provides a basic core of phenotypic expression.

\section{REFERENCES}

Fukuda S, Midoro K, Kamei T, Gyoten M, Kawano Y, Ashida Y, Nagaya H. Inhibition of allergic dermal inflammation by the novel imidazopyridazine derivative TAK-427 in a guinea pig experimental model of eczema. J Pharmacol Exp Ther. 2002; 303: 1283-90.

Gutermuth J, Ollert M, Ring J, Behrendt H, Jakob T. Mouse models of atopic eczema critically evaluated. Int Arch Allergy Immunol. 2004; 135: 262-76. 
Jin H, He R, Oyoshi M, Geha R. Animal models of atopic dermatitis. J Invest Dermatol. 2009; 129: 31-40.

Lee KS, Jeong ES, Heo SH, Seo JH, Jeong DG, Choi YK. A novel model for human atopic dermatitis: Application of repeated DNCB patch in BALB/c mice, in comparison with NC/Nga mice. Lab Anim Res. 2010: 26: 95-102.

Lorch G, Hillier A, Kwochka KW, Saville WA, LeRoy BE. Results of intradermal tests in horses without atopy and horses with atopic dermatitis or recurrent urticaria. Am J Vet Res. 2001; 62: 1051-59.

Matsuoka H, Maki N, Yoshida S, et al: A mouse model of the atopic eczema/dermatitis syndrome by repeated application of a crude extract of house-dust mite Dermatophagoides farinae. Allergy 2003; 58: $139-45$.

Mueller RS, Fieseler KV, Fettman MJ, Zabel S, Rosychuk RA, Ogilvie GK, Greenwalt TL. Effect of omega-3 fatty acids on canine atopic dermatitis. J Small Anim Pract. 2004; 45: 293-97.

Nolte T, Zadeh-Khorasani M, Safarov O, Rueff F, Varga R, Herbach N, Wanke R, Wollenberg A, Mueller T, Gropp R, Wolf E, Siebeck M. Induction of oxazolone-mediated features of atopic null mice engrafted with $\gamma$ dermatitis in NOD-scid IL2R human peripheral blood mononuclear cells. Dis Model Mech. 2013; 6: 125-34.

Schleifer SG, Willemse T. Evaluation of skin test reactivity to environmental allergens in healthy cats and cats with atopic dermatitis. Am J Vet Res. 2003; 64: 773-78.

Tanaka A, Matsuda H. Animal models of atopic eczema. In: Handbook of atopic eczema. Ring J, Przybilla B, Ruzicka T (eds). 2nd edi. Berlin, Springer-Verlag, 2006, pp 410-16.

Takeda K, Gelfand EW. Mouse models of allergic diseases. Curr Opin Immunol. 2008; 21: 660-65.

\section{PRECAUTION}

DNCB is toxic when inhale, swallow or in contact with skin

Wear gloves when handle DNCB solution

Keep the container of DNCB tightly closed

In case of contact with eyes, flush with copious amount of water for at lease $15 \mathrm{~min}$ 
Your feedback about this paper

1. Number of times you have read this paper 0

2. Quality of paper Click

3. Your comments

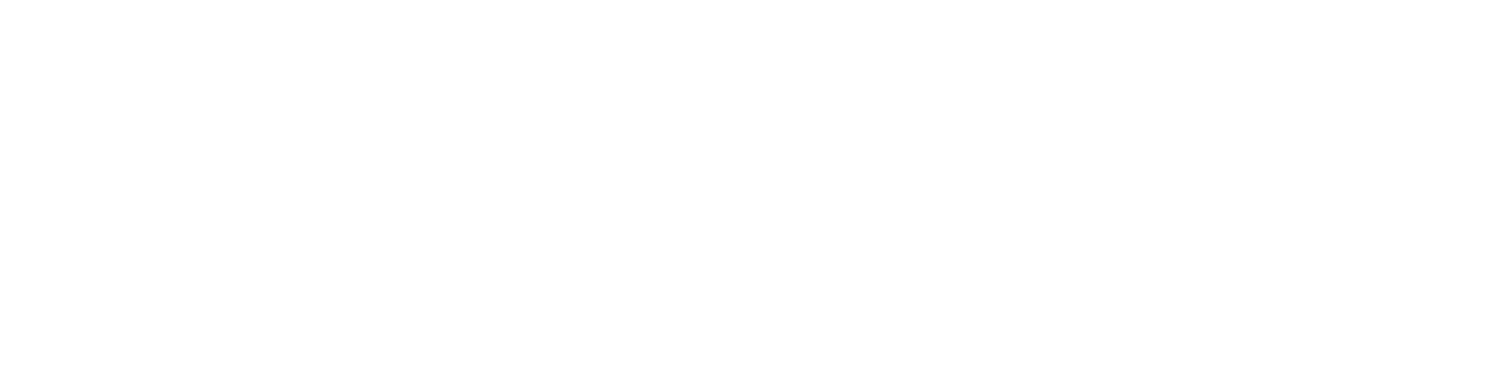

